\title{
To Study the Properties of Concrete using Bagasse Ash on M-25 Grade of Concrete
}

\author{
Amit* and Sahil Goel \\ R.P. Educational Trust Group of Institutions, Karnal, Haryana, India \\ Received 12 May 2018, Accepted 14 July 2018, Available online 16 July 2018, Vol.8, No.4 (July/Aug 2018)
}

\begin{abstract}
The utilization of the industrial waste products leads to the development of sustainable concrete. The use of industrial and agricultural waste in the construction industries not only reduces the consumption of natural resources but also nuisance of these waste materials. They not only reduce the cost of construction but also save the environment due to their sustainable disposal solution. Researchers are trying to find out the alternate materials of cement in concrete production to minimize the emission of carbon dioxide during cement manufacturing. Sugarcane bagasse ash is the fibrous agricultural waste material which is produced in enormous quantities in India and obtained as a result of combustion of sugarcane bagasse in the boilers at high temperatures. The ash contains large amount of silica and therefore can be used as a substitution of cement. In the present study, sugarcane bagasse ash is used as a partial replacement of cement by $0 \%, 5 \%, 10 \%, 15 \%$ and $20 \%$ by weight of cement.
\end{abstract}

Keywords: Concrete, Portland Cement, Bagasse Ash

\section{Introduction}

Concrete is used as a construction material to a great extent in the world. It is the second most consumed material in the world after water. Concrete has many applications such as building construction, dams, bridges and under water construction etc. (Nasir Shafiq, 2014). About 7.23 billion tons of concrete is produced every year. There are some negative impacts of more production of concrete like continuous extensive extraction of minerals from natural resources; those will lead to ecological imbalance. Utilization of agricultural, industrial and agroindustrial by-products in concrete production has become an attractive area to the researchers worldwide. At present, there has been employed an attempt to utilize the large amount of Sugarcane Bagasse Ash (SCBA), the residue from a sugar industry and the bagasse-biomass fuel in electric generation industry. Sugarcane contains about $30 \%$ bagasse while its sugar recovery is about $10 \%$, and the bagasse leaves about $8 \%$ bagasse ash as a residue. When this waste is burned under controlled conditions, it turns into ash having amorphous silica $\left(\mathrm{SiO}_{2}\right)$, which is pozzolanic in nature (Mulay Sachin, 2017). Utilization of such wastes as cement replacement materials also as mineral

*Corresponding author's ORCID ID: 0000-0002-7989-0637 DOI: https://doi.org/10.14741/ijcet/v.8.4.11 admixture can reduce the cost of concrete and also minimize the negative environmental effects menacing by the disposal of these wastes. M25 grade of concrete was prepared to study the durability of concrete in terms of resistance of concrete specimens under the exposure of chloride and sulphate attack at exposure time of 7, 28 and 62 days after 28 days of water curing. The concrete specimens containing of bagasse ash as a partial replacement of cement subjected to chloride and sulphate attack had better resistance in comparison to the control mix.

\section{Materials}

In the present study, cement, fine aggregates, coarse aggregates, water and bagasse ash were used. The properties of the various materials used in this work are given in the table 2.2 to 2.6

\subsection{Cement}

Cement as a binder used in the construction that set, harden and binds the other materials (Rao B. Someswara, 2015). The ordinary Portland cement of grade OPC-43 is used in this present study. The various tests were done to determine the physical properties of cement as per IS: 8112-1989 and have been given in the table 2.1 
Table 2.1 Physical Properties of Cement

\begin{tabular}{|c|c|c|c|}
\hline Sr No & Characteristics & Values Obtained & Values as per IS 8112:1989 \\
\hline 1 & Consistency & $29 \%$ & - \\
\hline 2 & Initial Setting Time & 124 minutes & Not Less than 30 minutes \\
\hline 3 & Final Setting Time & 196 minutes & Not Greater than 600 minutes \\
\hline 4 & Fineness & 4 & Not More than 10 \\
\hline 5 & Specific Gravity & 3.12 & - \\
\hline 6 & Compressive Strength (3 Days, 7 Days, 28 Days ) & $25.3,35.56,45.23$ & $23,33,43$ \\
\hline
\end{tabular}

\subsection{Fine Aggregates}

The material which passes through $4.75 \mathrm{~mm}$ sieve is termed as fine aggregate. Natural coarse sand was used in the present work. The physical properties of fine aggregates are given in the table 2.2

Table 2.2 Physical Properties of Fine Aggregates

\begin{tabular}{|c|c|c|}
\hline Sr. No. & Characteristics & Value \\
\hline 1. & Type & Natural sand \\
\hline 2. & Specific Gravity & 2.60 \\
\hline 3. & Fineness Modulus & 3.18 \\
\hline 4. & Grading Zone & Type II \\
\hline 5. & Bulk Density(Loose), $\mathrm{kg} / \mathrm{m}^{3}$ & 1575 \\
\hline 6. & $\begin{array}{c}\text { Bulk Density(compacted), } \\
\mathrm{kg} / \mathrm{m}^{3}\end{array}$ & 1770 \\
\hline
\end{tabular}

\subsection{Natural Coarse Aggregate}

Coarse aggregate which are locally able to be used of the maximum size of $20 \mathrm{~mm}$ is used in this study. The properties of the coarse aggregates are given in the table 2.3.

Table 2.3 Physical Properties of Coarse Aggregates

\begin{tabular}{|c|c|c|}
\hline Sr. No. & Characteristics & Value \\
\hline 1. & Type & Broken Stone \\
\hline 2. & Specific Gravity & 2.58 \\
\hline 3. & Fineness Modulus & 6.89 \\
\hline 4. & Bulk Density(Loose), $\mathrm{kg} / \mathrm{m}^{3}$ & 1350 \\
\hline 5. & Bulk Density(compacted), $\mathrm{kg} / \mathrm{m}^{3}$ & 1490 \\
\hline
\end{tabular}

\subsection{Bagasse Ash}

SCBA was collected from open lands near sugar factory in Yamuna Nagar, Haryana, India. Factory ash which contains high carbon content that was burnt at controlled temperature $650^{\circ} \mathrm{C}$ for 1 hour and was ground before use(Gar Parisa Setayesh, 2017). It was in powdered form and fine in nature.

\subsection{Water}

The water used for concreting should be good quality and free from the injurious salts. In the current work, tap water of lab was used for the mixing and curing purposes.

\section{Experimental Work}

The nine specimens of size $150 \mathrm{~mm} \times 150 \mathrm{~mm} \times 150 \mathrm{~mm}$ were casted for each mix proportion to determine the mass loss of concrete specimens when subjected under the exposure of $5 \% \mathrm{MgSO}_{4}$ solution and nine specimens of size $150 \mathrm{~mm} \times 150 \mathrm{mmx} 150 \mathrm{~mm}$ were casted for each mix proportion to determine the mass loss of concrete specimens when subjected under the exposure of $5 \%$ $\mathrm{NaCl}$ solution. The set of 3 cubes were tested at 7, 28 and 62 days respectively. The three cubes were taken out from solution, surface dried and weighed at the respective testing age. The mass and strength of the concrete cubes under the exposure of 7, 28 and 62 days was compared with that of water cured specimens at 35,56 and 90 days respectively. The weight and strength loss percentage was determined at 7, 28 and 62 days.

\section{Results and Discussion}

\subsection{General}

In the present study, the bagasse ash was used as a partial replacement of cement to study the workability, strength and durability properties of concrete at different curing age. The results obtained from the tests carried out on concrete containing bagasse ash were presented and discussed in this chapter. A comparison of the results also has been made to evaluate the effect of bagasse ash on the fresh, hardened and durability properties of bagasse ash concrete.

\subsection{Experimental Results}

The various specimens were tested to evaluate the resistance of bagasse ash concrete against the sulphate and chloride solution. The results are given in the table 4.1 to 4.5 and variation of Resistance against Chemical Attack and Magnesium Sulphate Attack.

\subsubsection{Resistance against Chemical Attack}

The durability properties of concrete using bagasse ash as a partial replacement of cement have been studied. The durability properties were studied in terms of resistance of concrete specimens under the exposure of magnesium sulphate and sodium chloride solution attack at different curing age and compared with 
normal water curing. After 28 days of water curing, the specimens were taken out from the curing tank, surface dried, weighed and immersed in sulphate and chloride solution for the respective periods. At the required time, the specimens were taken out from the solution, weighed and tested for compressive strength. Thus, the loss in mass and strength was determined after immersion in solution at required age.

\subsubsection{Magnesium Sulphate Attack}

\section{Mass loss}

The loss in mass of concrete specimens consisting of bagasse ash was measured at 7, 28 and 62 days of exposure to magnesium sulphate solution. The loss in mass of concrete using various percentage of has been given in table 4.1 and illustrated in fig. 4.1. The mass loss varied from $1.87 \%$ to $2.78 \%, 3.08 \%$ to $4.12 \%$ and $4.11 \%$ to $5.64 \%$ at 7,28 and 62 days of exposure to sulphate solution attack.

Table 4.1 Mass loss in Concrete Specimens under Sulphate Attack

\begin{tabular}{|c|c|c|c|}
\hline \multirow{2}{*}{ Mix No. } & \multicolumn{3}{|c|}{ Exposure time } \\
\cline { 2 - 4 } & 7 days (\%) & 28 days (\%) & 62 days (\%) \\
\hline B0 & 2.78 & 4.12 & 5.64 \\
\hline B1 & 2.43 & 3.68 & 5.13 \\
\hline B2 & 2.12 & 3.42 & 4.73 \\
\hline B3 & 1.87 & 3.08 & 4.11 \\
\hline B4 & 2.7 & 3.96 & 5.33 \\
\hline
\end{tabular}

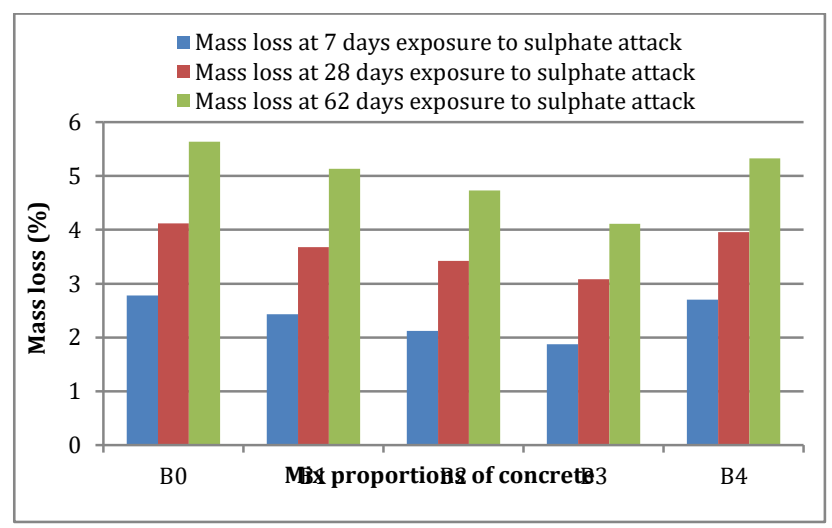

Fig. 4.1 Mass loss of Concrete Specimens Subjected to Sulphate Solution Attack

The mass loss of the concrete cube specimens of mix B1, B2, B3 and B4 under the exposure of sulphate solution decreased by $32.73 \%$ to $2.88 \%, 25.24 \%$ to $3.88 \%$ and $27.12 \%$ to $5.50 \%$ at 7,28 and 62 days in comparison to control mix.

Strength loss

The effect of using bagasse ash in concrete on loss in strength due to sulphate attack has been given in table 4.2 and illustrated in fig. 4.2.
Table 4.2 Compressive Strength of Concrete Subjected to Sulphate Attack

\begin{tabular}{|c|c|c|c|}
\hline \multirow{2}{*}{ Mix No. } & \multicolumn{3}{|c|}{ Exposure time } \\
\cline { 2 - 4 } & $\begin{array}{c}\text { 7 Days } \\
\text { Strength(MPa) }\end{array}$ & $\begin{array}{c}\text { 28 Days } \\
\text { Strength(MPa) }\end{array}$ & $\begin{array}{c}\text { 62 Days } \\
\text { Strength(MPa) }\end{array}$ \\
\hline B0 & 31.17 & 33.56 & 35.76 \\
\hline B1 & 34.75 & 35.16 & 37.1 \\
\hline B2 & 35.1 & 36.47 & 38.58 \\
\hline B3 & 36.81 & 38.54 & 40.12 \\
\hline B4 & 33.8 & 34.1 & 36.19 \\
\hline
\end{tabular}

- Compressive strength of concrete at 7 days subjected to sulphate attack - Compressive strength of concrete at 28 days subjected to sulphate attack - Compressive strength of concrete at 62 days subjected to sulphate attack

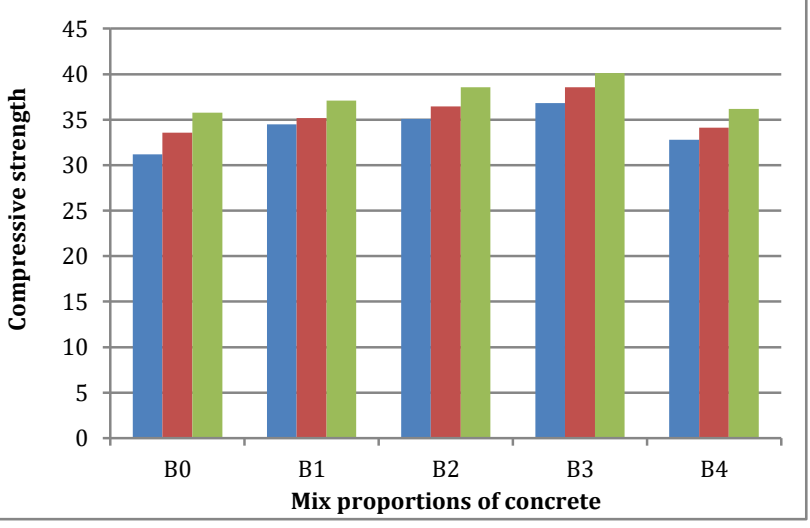

Fig. 4.2 Compressive Strength of Concrete Specimens Subjected to Sulphate Attack

The compressive strength of the concrete specimens under the sulphate attack increased for all the mix proportions and also with the curing age. The compressive strength of concrete varied from 31.17 $\mathrm{MPa}$ to $36.81 \mathrm{MPa}$, 33.56 MPa to $38.54 \mathrm{MPa}$ and 35.76 $\mathrm{MPa}$ to $40.12 \mathrm{MPa}$ at 7, 28 and 62 days respectively exposure to sulphate solution attack. The compressive strength increased by $4.97 \%$ to $15.32 \%, 1.58 \%$ to $12.92 \%$ and $1.19 \%$ to $10.87 \%$ at 7,28 and 62 days exposure to sulphate attack respectively. The mix B3 was found to be most effective in resisting the sulphate attack. The resistance of concrete specimens against the sulphate attack was higher than that of control mix due to its filling effect and pozzolanic reaction. The filling effect fills the voids of concrete specimen which did not permit the sulphate ions into specimens and consequently did not damage the specimens against sulphate attack like control mix. The loss in strength of concrete specimens under the exposure of sulphate attack at 7, 28 and 62 days has been studied. The compressive strength of the water cured specimens consisting of bagasse ash had higher values than that of specimens subjected to sulphate attack at 7,28 and 62 days. 


\subsubsection{Sodium Chloride Attack}

The influence of bagasse ash on the concrete specimens subjected to sodium chloride solution on the mass and strength has been studied. The change in mass and strength was observed and compared with the control mix and normal water curing.

\section{Mass loss}

The loss in mass of the concrete cubes specimens using bagasse ash under the exposure of sodium chloride solution at 7, 28 and 62 days has been studied. The effect of bagasse ash on the mass loss and strength loss has been given in table 4.3 and illustrated in fig. 4.3

Table 4.3 Loss in Mass of Concrete Specimens Due to Chloride Attack

\begin{tabular}{|c|c|c|c|}
\hline \multirow{2}{*}{ Mix No. } & \multicolumn{3}{|c|}{ Exposure time } \\
\cline { 2 - 4 } & 7 Days(\%) & 28 Days(\%) & 62 Days(\%) \\
\hline B0 & 2.13 & 3.38 & 4.18 \\
\hline B1 & 1.98 & 2.89 & 3.76 \\
\hline B2 & 1.76 & 2.67 & 3.48 \\
\hline B3 & 1.14 & 2.17 & 2.98 \\
\hline B4 & 2.07 & 3.1 & 3.99 \\
\hline
\end{tabular}

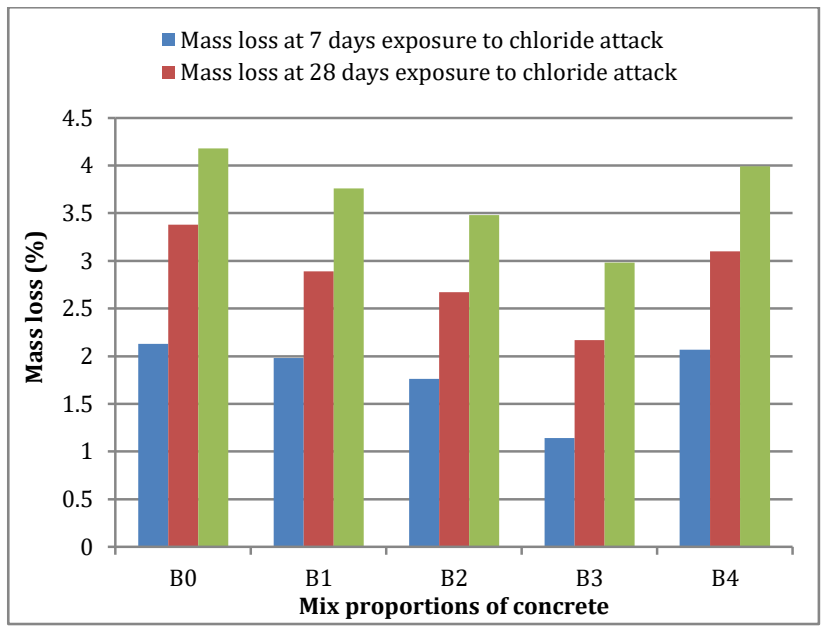

Fig. 4.3 Mass loss of Concrete Specimens Subjected to Chloride Attack

The loss of mass decreased for all the replacement levels and all the curing age. For mix B1, B2, B3 and B4; the mass loss of concrete specimens decreased by $2.82 \%$ to $41.46 \%, 8.28 \%$ to $35.80 \%$ and $4.55 \%$ to $28.70 \%$ in comparison to control mix. The minimum mass loss due to sodium chloride attack was for B3 mix at all curing age.

\section{Strength loss}

The compressive strength of the concrete cube specimens under the exposure of sodium chloride at 7 , 28 and 62 days has been studied and given in table 4.4 and variation in the compressive strength has been shown in fig. 4.4
Table 4.4 Strength loss of Concrete Due to Chloride Attack

\begin{tabular}{|c|c|c|c|}
\hline \multirow{2}{*}{ Mix No. } & \multicolumn{3}{|c|}{ Exposure time } \\
\cline { 2 - 4 } & $\begin{array}{c}\text { 7 Days } \\
\text { Strength(MPa) }\end{array}$ & $\begin{array}{c}\text { 28 Days } \\
\text { Strength(MPa) }\end{array}$ & $\begin{array}{c}\text { 62 Days } \\
\text { Strength(MPa) }\end{array}$ \\
\hline B0 & 32.31 & 34.48 & 36.72 \\
\hline B1 & 35.02 & 36.72 & 38.15 \\
\hline B2 & 36.17 & 37.84 & 39.2 \\
\hline B3 & 37.79 & 39.41 & 41.58 \\
\hline B4 & 33.75 & 34.14 & 36.85 \\
\hline
\end{tabular}

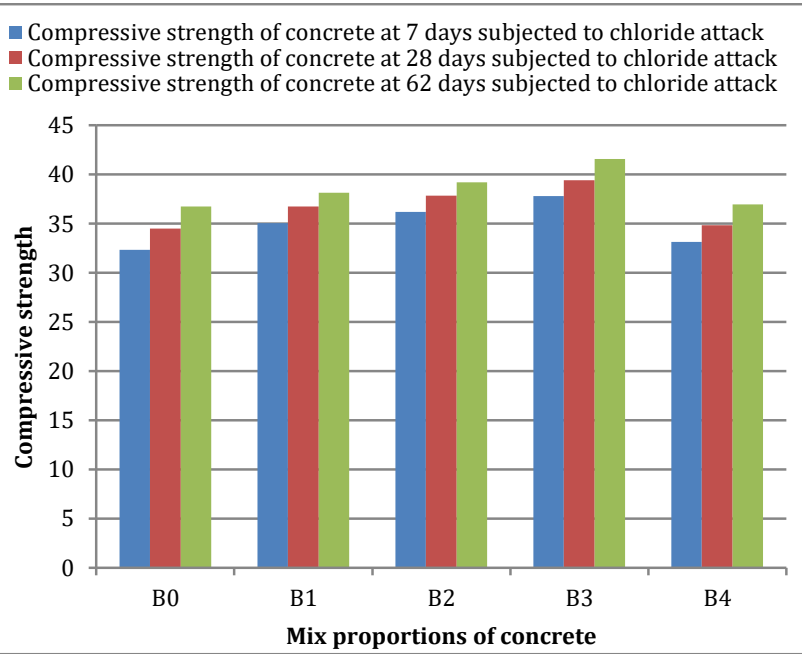

Fig. 4.4 Variation of Concrete Subjected to Chloride Solution

The strength of the concrete specimens under the exposure of chloride attack varied from $32.31 \mathrm{MPa}$ to 38.79 $\mathrm{MPa}$, to $34.48 \mathrm{MPa}$ to $39.41 \mathrm{MPa}$ and $36.72 \mathrm{MPa}$ to $41.58 \mathrm{MPa}$ at 7, 28 and 62 days. The compressive strength of concrete increased by $2.53 \%$ to $14.5 \%$, $1.03 \%$ to $12.51 \%$ and $0.35 \%$ to $11.68 \%$ at 7,28 and 62 days of exposure to chloride attack in comparison to control mix. The bagasse ash upto $15 \%$ increased the resistance of concrete specimens against the chloride attack after that it decreased the resistance against the chloride attack.

The bagasse ash increased the strength of concrete under the exposure of chloride attack in comparison to the control mix which may be due to filling effect of bagasse ash and pozzolanic reaction of bagasse ash. The filling nature of bagasse ash filled the pores of concrete specimens which restrain the movements of chloride ions into the concrete thus increased the strength of concrete.

The compressive strength of concrete specimens immersed into chloride solution was lower in comparison to concrete specimens immersed in normal water curing.

\subsubsection{Cost analysis}

To check the feasibility of concrete in terms of economy, the cost analysis of the concrete was also 
done. The price of the materials (in INR) used in this work has been given in table 4.5. The cost of the control mix i.e. without bagasse ash of M25 was Rs. 5246. The cost of the concrete decreased with the increase in bagasse ash content.

Table 4.5 Price of Materials, $\mathrm{kg} / \mathrm{m}^{3}$

\begin{tabular}{|c|c|c|c|c|}
\hline $\begin{array}{c}\text { Materials, } \\
\left(\mathrm{kg} / \mathrm{m}^{3}\right)\end{array}$ & Cement & Sand & Aggregates & $\begin{array}{c}\text { Bagasse } \\
\text { ash }\end{array}$ \\
\hline Price (INR) & 6.5 & 1.1 & 1.8 & 0.50 \\
\hline
\end{tabular}

The cost analysis of the concrete in cubic meter gas been illustrated in fig. 4.5. The cost of the concrete decreased with the use of bagasse ash by $2.15 \%$, $4.29 \%, 6.44 \%$ and $8.58 \%$ in comparison to the control mix.

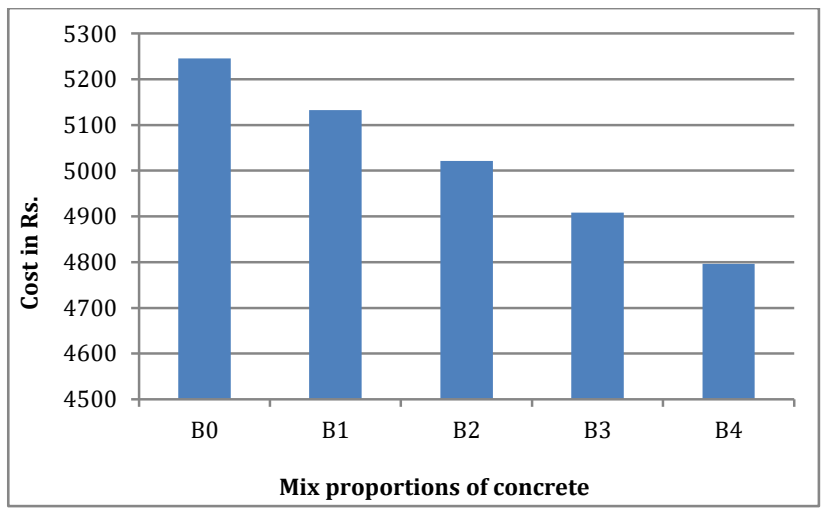

Fig. 4.5 Cost Analysis of Bagasse Ash Concrete

The reduction in cost of concrete production made the concrete economical by using bagasse ash in the concrete. The utilization of bagasse ash not only reduced the cost of the concrete but also improved the strength of the concrete. The inclusion of bagasse ash into concrete reduced the problems concerned with the bagasse ash which save environment and also resolved their dumping issue. The incorporation of bagasse ash into concrete also conserves the quantity of cement by replacing it with bagasse ash. The use of bagasse ash also conserved the natural resources and energy. The bagasse ash found as a cost effective and strength improver material supplementary industrial by products.

\section{Conclusion}

On the basis of experimental investigation carried out following conclusion can be drawn. The Concrete consist of Portland cement, aggregates and water. In the present study, bagasse ash is used as a partial replacement of cement to study durability properties i.e. resistance of concrete specimens against the chemical attack at 7, 28 and 62 days under the exposure of chemical and sulphate attack and compared with concrete without bagasse ash. Bagasse ash (15\%) had higher resistance to magnesium sulphate and sodium chloride solution attack at all the curing age. The introduction of bagasse ash in concrete not only reduces the cost of construction but also reduce the content of cement which consequently reduces the consumption of natural resources and energy. The use of bagasse ash also saves the environment by reducing emission of carbon dioxide and also reducing agro waste by utilizing it into concrete. Bagasse ash found to be efficient materials as a replacement of cement.

\section{References}

A. Rajasekar, K. Arunachalam, M. Kottaisamy, V. Sarsawwathy (2018), Durability Characteristics of Ultra high Strength Concrete with Treated Sugarcane Bagasse Ash, Construction and Building Material, Elsevier, pp 350-356

Mulay Sachin, Vesmawala Gaurang, Patil Yogesh, Gholap Vikas (2017), Experimental Investigation of Sugarcane Bagasse Ash Concrete Under Sodium Hydroxide Solution, American Journal of Civil Engineering, vol. 5, issue no. 1, pp. 1-8

Rao B.Someswara, LalN.Vidya Sagar, Naveen G. (2015), Durability Studies on Concrete and Comparison with Partial Replacement of Cement with Rice Husk Ash and Sugarcane Bagasse Ash in Concrete, Int. Journal of Engineering Research and Applications, ISSN: 22489622, Vol. 5, Issue 11, (Part - 4) November pp.52-58

Rerkpiboon Aukkadet, Tangchirapat Weerachart, Jaturapitakkul Chai (2015), Strength, chloride resistance, and expansion of concretes containing ground bagasse ash, Construction and Building Materials, vol. 101, pp. 983-989

Jalam Usman Aliyu, Jalam Abdurrahman Aliyu (2016), Sale Ibrahim M., Cost Evaluation of Utilising Building Materials Derived from Agricultural Waste as Sustainable Materials for Lightweight Construction, Economic and Environmental Studies, Vol. 16, No. 4, pp. 673-685.

Nasir Shafiq et al. (2014), Effect of sugarcane Bagasse ash on Sulphate resistance of concrete,International joutnal of Enhanced Research in Science technology and engineering, vol-3,pp 64-67

Nuntachai et al. (2009), Effect of loss on ignition of Ground bagasse ash on compressive strength and Sulphate resistance of mortars, ScienceDirect, vol 123, pp-3523-3531

Mini Vishakarma et al. (2015),Study on the Strength and Cost analysis of Concrete with Sugarcane Bagasse ash, International journal of technical research and Application, vol 3, pp 310-312

Gar Parisa Setayesh, Suresh Narayana, Bindiganavile Vivek (2017), Sugar cane bagasse ash as a pozzolanic admixture in concrete for resistance to sustained elevated temperatures, Construction and Building Materials, vol. 153, pp. 929-936 